ANUVA Volume 2 (3): 291-298, 2018

Copyright (C2018, ISSN: 2598-3040 online

Available Online at: http://ejournal.undip.ac.id/index.php/anuva

\title{
Pencarian Katalog dalam Online Public Access Catalog Menggunakan Boolean Logic
}

\author{
Athanasia Octaviani Puspita Dewi ${ }^{1 *}$ \\ ${ }^{1}$ Program Studi S-1 Ilmu Perpustakaan, Fakultas Ilmu Budaya, Universitas Diponegoro, \\ Jl. Prof. Soedharto, SH, Kampus Undip Tembalang, Semarang, Indonesia \\ *) Korespondensi: athanasia.dewi.9@gmail.com
}

\begin{abstract}
[Title: Catalog Search in Online Public Access Catalog using Boolean Logic] This article discusses how boolean logic is connected to the database in the Online Public Access Catalog (OPAC), so can find something related to the keywords entered by the user. The results of this study are boolean logic included in the Structured Query Language $(S Q L)$, while the query itself is placed in the coding contained in the OPAC system. Boolean logic insertion aims to enable users of the OPAC system to find information according to what they want to find. Librarians are expected to learn more to add insight and ability to prepare reliable OPACs to prepare themselves for competition in information technology in the library.
\end{abstract}

Keywords: Online Public Access Catalog (OPAC), boolean logic; database; SQL; query

\begin{abstract}
Abstrak
Artikel ini membahas bagaimana logika boolean terhubung dengan basis data dalam Online Public Access Catalog (OPAC), sehingga dapat menemukan sesuatu yang terkait dengan kata kunci yang dimasukkan oleh pengguna. Hasil dari penelitian ini adalah logika boolean dimasukkan dalam Structured Query Language (SQL), sedangkan query itu sendiri ditempatkan dalam pengkodean yang terdapat dalam sistem OPAC. Penyisipan logika boolean bertujuan untuk memungkinkan pengguna sistem OPAC dapat menemukan informasi sesuai dengan apa yang ingin dicari. Para pustakawan diharapkan untuk belajar lebih banyak untuk menambah wawasan dan kemampuan dalam menyiapkan OPAC yang handal untuk mempersiapkan diri menghadapi persaingan teknologi informasi di bidang perpustakaan.
\end{abstract}

Kata kunci: Online Public Access Catalog (OPAC); logika boolean; basis data; SQL; query

\section{Pendahuluan}

Kemajuan teknologi informasi yang mempermudah pekerjaan manusia semakin lama semakin pesat perkembangannya. Demikian pula di bidang perpustakaan, dulu orang yang akan mencari informasi harus dengan susah payah mencari dengan tumpukan kertas yang sangat banyak, namun pada sekarang ini manusia dimudahkan dengan munculnya OPAC. Koleksi yang ada di sebuah perpustakaan cukup diinputkan ke dalam sistem yang terhubung dengan media penyimpanan database. Pustakawan bisa menginputkan kata kunci yang diinginkan, dan kemudian sistem OPAC akan mencari ke dalam database sesuai dengan kata kunci.

Selama ini para pustakawan hanya bisa menggunakan sistem OPAC tanpa mengetahui bagaimana cara kerja sistem tersebut. Oleh sebab itu, perlu dikaji bagaimana penelusuran pencarian kata kunci ke dalam database. Tujuan penelitian ini adalah untuk mengetahui bagaimana boolean logic digunakan dalam penelusuran. Manfaat dari penelitian ini adalah untuk menambah pengetahuan pembaca, khususnya pustakawan supaya tidak hanya bisa menggunakan, tetapi mengetahui bagaimana 
penelusuran itu bekerja. Metode penelitian yang digunakan adalah studi literatur, dengan menganalisa tulisan-tulisan dari beberapa sumber.

\section{Landasan Teori}

\subsection{OPAC}

Menurut Corbin yang dikutip oleh Hasugian (2009) Online Public Access Catalog adalah katalog yang di dalamnya terdapat informasi bibliografi dari koleksi yang terdapat di perpustakaan, OPAC ini disimpan di dalam basis data sistem otomasi perpustakaan, dan dapat dilihat oleh pemustaka pada saat pemustaka mencarinya secara online. Sedangkan menurut Saleh dan Mustafa katalog online atau OPAC adalah sistem katalog perpustakaan dengan memanfaatkan perangkat keras komputer yang di dalamnya terdapat basis data yang dirancang dan dibuat sendiri menurut kebutuhan perpustakaan tersebut. Di dalam katalog tersebut terdapat informasi bibliografis dan letak koleksi tersebut disimpan. OPAC dirancang untuk mempermudah pengguna, baik itu pemustaka maupun pustakawan supaya dengan mandiri dapat mencari informasi koleksi di suatu perpustakaan (1992). Kemudian menurut Horgan yang dikutip oleh Hasugian (2009: 154) menyatakan bahwa OPAC adalah sebuah sistem temu kembali informasi yang terdiri dai input (bisa berupa nama pengarang atau judul koleksi yang akan dicari), kemudian koleksi tersebut akan dicari di dalam basis data perpustakaan, sehingga dapat menampilkan output nerupa hasil pencarian koleksi beserta informasinya.

Dari uraian di atas dapat dijelaskan bahwa OPAC adalah sistem katalog online yang berisikan informasi bibliografi dari satu atau beberapa koleksi yang terdapat di perpustakaan yang dapat digunakan oleh pengguna untuk menelusur basis data katalog dan berfungsi sebagai sarana untuk memeriksa status dari suatu bahan pustaka atau koleksi perpustakaan. Dibandingkan dengan katalog kartu atau jenis katalog lainnya, katalog online lebih efisien karena memiliki lebih banyak titik akses dan lebih fleksibel. Penelusuran koleksi dengan sistem OPAC dapat dilakukan dengan menggunakan kata kunci seperti judul, pengarang, subjek dan informasi lainnya dari suatu koleksi yang ingin dicari sehingga dapat mempermudah pengguna menemukan koleksi yang dicarinya. OPAC merupakan sarana penghubung antara sekumpulan koleksi pada suatu perpustakaan dengan pengguna perpustakaan. Dengan OPAC pengguna dapat melakukan proses temu balik informasi dengan mudah dan cepat.

Menurut Tedd yang dikutip oleh Hasugian (2009) menjelaskan perkembangan sistem OPAC dan otomasi perpustakaan sebagai berikut:

1. Tahun 1960 sampai Awal Tahun 1970-an

Pada tahun 1960-an, sistem pencarian katalog perpustakaan dengan menggunakan bantuan komputer secara online masih dianggap tidak mungkin terjadi. Pada awal 1970-an beberapa perpustakaan mulai menggunakan komputer untuk pengembangan sistem informasi secara internal.

2. Pertengahan Tahun 1970-an 
Di pertengahan tahun 1970 komputer sudah mulai digunakan untuk melakukan peminjaman dan pengembalian koleksi di perpustakaan. Di waktu-waktu ini juga mulai muncul sistem pengkatalogan yang dapat dimanfaatkan secara bersama pada beberapa perpustakaan.

3. Akhir Tahun 1970-an sampai Awal Tahun 1980-an

Pada kisaran waktu ini komputer mikro lebih dikenal sebab di dalamnya terdapat kemampuan untuk mengakses secara online terhadap penyimpanan file yang digunakan dalam sistem sirkulasi. Pada masa ini juga mulai populer sistem penjualan perangkat keras (hardware) dan perangkat lunak (software) secara paket.

\section{Pertengahan sampai Akhir Tahun 1980-an}

Masa ini adalah masa-masa dimana OPAC mulai berkembang, yang pada masa sebelumnya baru mulai dikenal saja. Banyak perpustakaan yang mulai beralih dari penggunaan katalog tradisional ke sistem OPAC, mereka menyediakan anggaran khusus untuk pengembangan sistem ini.

5. Tahun 1990-an

Di tahun ini mulai nampak perubahan besar yang terjadi pada sistem pengelolaan perpustakaan. Pembuat sistem membuat sistem baru yang dapat dijalankan pada sejumlah perangkat keras. Arsitektur dari beberapa sistem yang baru ini, memisahkan perangkat lunak (software) menjadi client dan server. Agar client dan server dapat saling berhubungan tanpa hambatan, maka dalam protokol komunikasi antar client dan server (client-server communication protocol) ditetapkan aturan-aturan yang digunakan untuk keperluan tersebut.

OPAC mengalami perkembangan yang pesat dari masa ke masa, dimulai dari tahun 1960 sampai dengan saat ini. Semua program aplikasi otomasi perpustakaan saat ini pun dapat dipastikan telah menggunakan OPAC sebagai media temu balik informasi. OPAC pada saat ini sudah terintegrasi dengan sistem otomasi perpustakaan. Jadi ketika menginstal sistem otomasi perpustakaan, akan secara otomatis juga akan terinstal OPAC di dalamnya. Penggunaan OPAC juga dapat disesuaikan dengan kebutuhan user, akankah semua koleksi bisa dicari melaui sistem OPAC, atau hanya koleksi tertentu saja yang bisa dicari denan menggunakan sistem OPAC.

\subsection{Boolean Logic}

Penelusuran dengan menggunakan OPAC dapat dilakukan dengan berbagai cara. Menurut Rowley yang dikutip oleh Hasugian (2001) mengemukakan bahwa ada beberapa jenis penelusuran yang dapat dilakukan melalui OPAC, yaitu:

1. Penelusuran dengan merawak (browser searching)

2. Penelusuran dengan memasukkan kata kunci (keyword searching) menggunakan satu atau lebih kata

3. Penelusuran frase, dengan memasukkan frase dalam kutipan

4. Penelusuran index-silang, misalnya menelusur lebih dari satu indeks dalam pernyataan penelusuran tunggal

5. Logika Boolean, didukung oleh operator AND, OR dan NOT. 
Operator aritmatika menghasilkan angka, sedangkan operator relational dan operator logika menghasilkan nilai true atau false. Boolean logic atau logika boolean adalah logika matematika yang menggunakan operator logika untuk menghasilkan output true atau false.

Contoh :

$8<5$ false, karena 8 tidak lebih kecil dari 5

3>-1 true, karena 3 lebih besar dari -1

Pada penelusuran dengan boolean logic, biasanya user dihadapkan dengan operator AND, OR, dan NOT.

1. Operator AND, adalah operator penghubung dengan kondisi bahwa kata pertama dan kata kedua dalam OPAC akan dicari secara bersamaan atau berdampingan.

Contoh: jika yang diinputkan ke dalam OPAC adalah 'perpustakaan' AND 'pustakawan', maka pencarian akan difokuskan dengan kedua kata tersebut yang muncul secara bersamaan.

2. Operator $\mathrm{OR}$, adalah operator penghubung dengan syarat jika kata pertama dan kata kedua dicari dalam pencarian OPAC, maka pencarian akan mencari sesuatu yang mengandung kata pertama, atau kata kedua, atau yang mengandung kedua kata tersebut.

Contoh: jika kata kunci untuk mencari yang akan kita cari adalah 'perpustakaan' OR ‘pustakawan', maka pencarian akan difokuskan pada kata 'perpustakaan' saja, atau fokus pada 'pustakawan', atau fokus pada 'perpustakaan' dan 'pustakawan'.

3. Pernyataan yang diawali dengan NOT, berarti bahwa pernyataan tersebut mempunyai nilai yang tidak mengandung pernyataan yang disebutkan.

Contoh: ketika user ingin mencari judul artikel yang tidak mengandung kata 'perpustakaan' maka user dapat mengetikkan kata 'perpustakaan' dan menggunakan operator NOT.

\subsection{Basis Data}

Basis data adalah suatu pengorganisasian sekumpulan data yang saling terkait sehingga memudahkan aktivitas untuk memperoleh informasi (Kadir, 2003: 254). Kaitan basis data dengan OPAC adalah semua informasi yang diakses melalui OPAC berasal dari basis data yang sebelumnya telah dimasukkan pustakawan melalui sistem otomasi perpustakaan. Dalam pengelolaan basis data, diperlukan perangkat lunak yang disebut dengan DBMS (Database Management System). Menurut Kadir DBMS adalah pernagkat lunak sistem yang memungkinkan para pemakai membuat, memelihara, mengontrol, dan mengakses basis data dengan cara yang praktis dan efisien (2003: 254).

Untuk mengakses basis data, pengguna perlu memahami bahasa khusus yang digunakan. Menurut Kadir (2003: 265) DBMS memiliki dua macam bahasa yang digunakan untuk mengelola dan mengorganisasikan data, yaitu:

- DDL (Data Definition Language)

DDL adalah perintah-perintah yang biasa digunakan oleh administrator basis data untuk mendefinisikan basis data. 
Contoh : CREATE TABLE, DROP TABLE

- DML (Data Manipulation Language)

DML adalah perintah-perintah yang digunakan untuk mengambil (SELECT), menambahkan (INSERT), mengubah (UPDATE), dan menghapus (DELETE) data dalam basis data.

Tabel 1. Daftar Pernyataan SQL (Kadir dan Terra, 2003: 510)

\begin{tabular}{cl}
\hline Pernyataan & \multicolumn{1}{c}{ Keterangan } \\
\hline CREATE TABLE & Untuk menciptakan tabel \\
DROP TABLE & Untuk menghapus tabel \\
SELECT & Untuk mengambil data \\
INSERT & Untuk menambahkan data \\
UPDATE & Untuk mengganti data \\
DELETE & Untuk menghapus data \\
\hline
\end{tabular}

Dua macam bahasa tersebut sering disebut dengan istilah SQL (Structured Query Language). Menurut Kadir dan Terra, SQL (Structured Query Language) adalah bahasa yang digunakan untuk mengakses basis data yang tergolong relasional. Standar SQL pada awal mulanya didefiniikan oleh ISO (International Standards Organizations) dan ANSI (the American National Standards Institute), yang dikenal dengan sebutan SQL86, standard terakhir pada saat buku berjudul Pengenalan Teknologi Informasi milik Kadir dan Terra disusun berupa SQL99 (2003: 510).

\section{Metode Penelitian}

Metode Penelitian yang digunakan dalam penelitian ini adalah kualitatif deskriptif. Penelitian dilakukan dengan cara mengumpulkan informasi dari beberapa sumber, kemudian membandingkan dengan apa yang biasanya dilakukan secara nyata oleh pembuat program aplikasi, dan disajikan secara deskriptif dengan memberikan contoh pada penjelasan kinerja logika boolean.

\section{Hasil dan Pembahasan}

Ketika pengguna melakukan penelusuran dengan menggunakan OPAC, secara tidak langsung pengguna telah menggunakan basis data. Basis data terletak terpisah dengan aplikasi OPAC, namun saling berhubungan. OPAC sendiri berisi user interface yang berfungsi untuk mengakses basis data, sedangkan basis data adalah tempat penyimpanan data-data dan informasi yang dibutuhkan oleh pengguna. OPAC bisa dibangun terpisah atau bersatu dengan sistem otomasi perpustakaan, itu semua tergantung pembuat aplikasi tersebut. OPAC dapat dibuat dengan menggunakan bahasa pemrograman apapun, sesuai dengan keahlian programmer atau bisa disesuaikan dengan permintaan pengguna aplikasi otomasi. Bahasa pemrograman yang digunakan untuk membuat aplikasi OPAC misalnya PHP, ASP.NET, Java, dll.

Jika sebuah aplikasi ingin memanfaatkan basis data, maka aplikasi yang dibuat dengan menggunakan bahasa pemrograman tersebut harus berisi koding yang di dalamnya diselipkan SQL. Di 
dalam SQL inilah query yang memuat boolean logic ditulis. Supaya lebih jelas dalam menggambarkan kinerja OPAC, basis data, dan SQL maka berikut ini adalah contoh dan penjelasannya:

Contoh dalam bahasan pada 2.2, jika pemustaka akan mencari buku yang tersimpan di dalam bibliografi dan yang judulnya terdapat kata 'perpustakaan' dan 'pustakawan', maka yang diinputkan ke dalam OPAC adalah 'perpustakaan' AND 'pustakawan', sedangkan query yang diketikkan oleh programmer adalah:

SELECT * FROM bibliografi WHERE judul LIKE '\%perpustakaan\%' AND judul LIKE '\%pustakawan\%'

Query inilah yang disisipkan ke dalam bahasa pemrograman, supaya pemustaka dapat menggunakannya melalui OPAC. Hasil dari query tersebut akan menampilkan data pada basis data dimana dalam basis data tersebut terdapat tabel data yang bernama bibliografi, menampilkan judul bibliografi yang mengandung kata 'perpustakaan' dan 'pustakawan' sekaligus.

Tabel 2. Daftar Kemungkinan Operasi dengan AND (Kadir, 2003: 291)

\begin{tabular}{ccl}
\hline Operand 1 & Operand 2 & Hasil \\
\hline Salah & Salah & Salah \\
Salah & Benar & Salah \\
Benar & Salah & Salah \\
Benar & Benar & Benar \\
\hline
\end{tabular}

Maksud logika pada baris 1 tabel 2 adalah bahwa jika judul bibliografi yang mengandung kata perpustakaan tidak ada, dan yang mengandung kata pustakawan tidak ada di dalam basis data, maka tidak akan memberikan hasil apapun. Baris 2 tabel 2 adalah bahwa jika judul bibliografi yang mengandung kata perpustakaan tidak ada, dan yang mengandung kata pustakawan ada di dalam basis data, maka tidak akan memberikan hasil apapun juga. Maksud dari baris 3 tabel 2 adalah bahwa jika judul bibliografi yang mengandung kata perpustakaan ada dalam basis data, dan yang mengandung kata pustakawan tidak ada di dalam basis data, maka tidak akan memberikan hasil apapun juga. Sedangkan maksud dari baris 4 tabel 2 adalah bahwa jika judul bibliografi yang mengandung kata perpustakaan ada dalam basis data, dan yang mengandung kata pustakawan juga terdapat di dalam basis data, maka akan memberikan hasil yaitu judul bibliografi yang mengandung kedua kata tersebut secara bersamaan.

Contoh dalam bahasan pada 2.2, jika pemustaka akan mencari buku yang tersimpan di dalam bibliografi dan yang judulnya terdapat kata 'perpustakaan' atau 'pustakawan', maka yang diinputkan ke dalam OPAC adalah 'perpustakaan' OR 'pustakawan', sedangkan query yang diketikkan oleh programmer adalah:

SELECT * FROM bibliografi WHERE judul LIKE '\%perpustakaan\%' OR judul LIKE '\%pustakawan\%' 
Tabel 3. Daftar Kemungkinan Operasi dengan OR (Kadir, 2003: 292)

\begin{tabular}{ccc}
\hline Operand 1 & Operand 2 & Hasil \\
\hline Salah & Salah & Salah \\
Salah & Benar & Benar \\
Benar & Salah & Benar \\
Benar & Benar & Benar \\
\hline
\end{tabular}

Dari baris 1 tabel 3 dapat dijelaskan bahwa jika judul bibliografi yang mengandung kata perpustakaan tidak ada, dan yang mengandung kata pustakawan tidak ada di dalam basis data, maka tidak akan memberikan hasil apapun. Baris 2 tabel 3 dapat dijelaskan bahwa jika judul bibliografi yang mengandung kata perpustakaan tidak ada, dan yang mengandung kata pustakawan ada di dalam basis data, maka akan memberikan hasil yaitu judul bibliografi yang mengandung kata pustakawan saja. Maksud dari baris 3 tabel 3 adalah bahwa jika judul bibliografi yang mengandung kata perpustakaan ada dalam basis data, dan yang mengandung kata pustakawan tidak ada di dalam basis data, akan memberikan hasil yaitu judul bibliografi yang mengandung kata perpustakaan saja. Sedangkan maksud dari baris 4 tabel 2 adalah bahwa jika judul bibliografi yang mengandung kata perpustakaan ada dalam basis data, dan yang mengandung kata pustakawan juga terdapat di dalam basis data, maka akan memberikan hasil yaitu judul bibliografi yang mengandung kedua kata tersebut secara bersamaan, judul bibliografi yang terdapat kata perpustakaan saja juga akan ditampilkan, dan juga judul bibliografi yang mengandung pustakawan saja akan ditampilkan.

Dari beberapa penjelasan tersebut dapat disimpulkan bahwa yang menentukan penggunaan $A N D, O R$, NOT bisa digunakan atau tidak bisa digunakan adalah pembuat program (programmer). Yang ditampilkan OPAC hanya murni tampilan saja, sedangkan fungsi-fungsi secara utuh hanya dapat dipahami oleh basis data administrator dan programmer.

\section{Simpulan}

Online Public Access Catalog (OPAC) adalah suatu sistem yang digunakan untuk mencari informasi tertentu yang terdiri dari user interface OPAC, koding dengan menggunakan bahasa pemrograman tertentu yang di dalamnya terdapat query, dan basis data. OPAC hanya bisa diakses jika semua koleksi sudah didigitalkan. Banyak kemudahan yang ditawarkan OPAC, sehingga pencarian dengan menggunakan OPAC ini banyak dipilih oleh pustakawan daripada menggunakan penelusuran katalog manual. Dengan semakin berkembangnya teknologi informasi di bidang perpustakaan, maka pustakawan diharapkan belajar lebih dalam lagi untuk menambah wawasan dan kemampuan supaya siap dalam mengahadapi dunia perpustakaan digital. 


\section{Daftar Pustaka}

Hasugian, Joner. 2001. Katalog Perpustakaan: Dari Katalog Manual Sampai Katalog Online (OPAC). Medan: UPT Perpustakaan USU. 2009. Dasar-Dasar Ilmu Perpustakaan dan Informasi. Medan: USU Press.

Kadir, Abdul. 2003. Pengenalan Sistem Informasi. Yogyakarta: Andi.

Kadir, Abdul dan Terra CH. Triwahyuni. 2003. Pengenalan Teknologi Informasi. Yogyakarta: Andi.

Saleh, A.R. dan B. Mustafa. (1992). Penggunaan Komputer untuk Pelayanan Informasi Perpustakaan. Jakarta: Kesaint Blanc. 